\title{
El estudio del significado mediante pruebas de sustitución de palabras
}

\section{Alfredo Fierro}

\author{
Universidad de Salamanca
}

El propósito de este informe es presentar una técnica general de investigación del significado lingüístico, así como algunos instrumentos de prueba y procedimientos de aplicación que la destinan al estudio de términos cargados de significación cultural y de juicios de valor.

En sustancia, la técnica consiste en pedir a un grupo de personas que sustituyan una palabra - siempre la misma y común a una lista de frasespor cualquier otra palabra que conserve en la mayor medida el sentido de la frase en que se halla. Como cada estrategia o técnica de investigación pretende contribuir, al lado de otras o mejor que otras, a la solución de determinados problemas planteados a la ciencia, comenzaré por señalar a qué género de cuestiones y también a qué líneas o niveles de cuestionamiento trata de responder la técnica que expongo. Responde, en particular, a cuestiones aparecidas en tres distintas tradiciones y disciplinas del estudio del significado: la filosofía del lenguaje, la semántica lingüística y la psicolingüística de la significación.

\section{ANTECEDENTES}

\subsection{En la filosofía}

En cuanto a antecedentes filosóficos del estado de la cuestión, importa remontarse a la teoría empirista o lógico-positivista del significado. Esta teoría dice que no sólo la verdad, también la significación de las proposiciones factuales, relativas a hechos, e igualmente en los términos que aparecen en ellas, se comprueba en la experiencia sensible a que se refieren. En su formulación primera y fuerte, el positivismo lógico deniega significación a todo enunciado no verificable; en consecuencia, niega significado asimismo a todo término que sólo pueda figurar en enunciados inverificables. Las proposiciones y los términos todos del lenguaje metafísico, del 
religioso, del ético-moral y aun político, son, por tanto, reputados carentes de sentido, vacíos, meras emisiones verbales sin contenido. Se les reconoce únicamente un valor emocional, no un sentido denotativo (Carnap, 1931; Ayer, 1965, 1971).

La propia tradición filosófica empirista había de traer decisivas rectificaciones de la posición positivista. Wittgenstein (1958) sugiere que, para buen número de palabras y de posiciones, el significado es el uso, la utilización efectiva en el lenguaje. Afirmar, dudar, creer, ordenar, pedir, prometer, indicar, permitir, etcétera, son otros tantos usos o juegos de lenguaje, significativos cada cual a su manera, no forzosamente según el criterio de verificabilidad. Es una sugerencia que recogen otros filósofos y teóricos del lenguaje (Austin, 1962; Ryle, 1949; Searle, 1969; Pike, 1972), cuya moraleja metodológica dice que la investigación del significado ha de abordar los términos en el contexto de sus diversos y particulares juegos o usos.

La técnica de sustitución de palabras (TSP) dentro de frases que corresponden a juegos, usos y contextos ( Settings») bien definidos, ha sido ideada, ante todo, para salir al paso de la afirmación positivista extrema de que términos y enunciados de los lenguajes metafísico, religioso, ético y político, en rigor carecen de significado, y aprovecha para ello la propuesta wittgensteiniana de examinar el significado mediante el uso, sirviéndose de la presentación de cada término en el conjunto de contextos en que puede ser utilizado.

Es una técnica ordenada al descubrimiento de significado en los lenguajes citados, pero ordenada a un descubrimiento empírico, contrastado en la experiencia y en eso trasciende las propuestas, sólo filosóficas, de Wittgenstein y de la filosofía del lenguaje ordinario. Con ella se operacionaliza y traslada a términos experimentales (o cuasi-experimentales) lo que los filósofos intérpretes del significado como uso aseveran como hipótesis o tesis especulativa, resultado de una inspección nada más fenomenológica. La operacionalización consiste, primero, en buscar distintas frases que sean muestras de ocurrencia lingüística de ciertos términos - tales como libertad, Dios, justicia, sentido, amor, etcétera- en todos sus usos o juegos lingüísticos; y, luego, en solicitar de un grupo determinado de personas, de hablantes acompetentes» (en el sentido que desde Chomsky se da a la competencia lingüística), que sustituyan el término en cuestión por algún otro que preserve lo mejor posible el sentido de la frase. Se asume que el significado de cada término vendrá dado por el conjunto de usos o juegos en que puede aparecer y que la obligada sustitución del término por otro diferente permitirá hacer emerger mejor el contenido semántico del mismo.

\subsection{En la lingüística}

La técnica de exploración del significado lingüístico mediante sustitución, en un conjunto de frases, del término que en cada caso está estudiándose, guarda relación, por otro lado, con algunos procedimientos, hipótesis y teorías, que tienen curso en la lingüística actual, originados casi siempre en la fonología y posteriormente extendidos a la lexicología y la semántica. Concretamente, la construcción de repertorios de frases para cada uno de los términos que, para ser investigados, son sometidos a la prueba de sustitución, obedece a un criterio lingüístico, destacado principalmente por el distribucionalismo (Harris, 1954 y 1951; Wells, 1947; Joos, 1957), 
teoría según la cual el sentido de un término viene definido por la totalidad de los contextos y ocurrenciạs en que puede aparecer.

El postulado distribucional exhibe visibles analogías con la caracterización wittgensteiniana del significado como uso, como conjunto de posibles usos y es satisfecho por la TSP en la fase de elaboración de los repertorios o listas de frases.

El primer paso de su estrategia operatoria, para cualquiera de los términos por investigar -v.gr., «libertad», «injusticia», «bondad», «fe», etcétera - consiste en construir un elenco completo y exhaustivo de sus posibles tipos de ocurrencia. Por supuesto, el número de actos de habla en que cada término puede presentarse es indefinido, potencialmente infinito. Sus contextos y usos, sin embargo, permanecen limitados y se hallan circunscritos a un «corpus» más o menos extenso que puede ser perfilado de modo empírico, como Greimas (1966: 1971, págs. 213-226) ha mostrado al desarrollar procedimientos lingüísticos para el establecimiento y delimitación del mismo. En particular, la comprobación de la exhaustividad del «corpus» se hace manifiesta cuando la añadidura de nuevos enunciados al conjunto resulta redundante con respecto a los enunciados ya presentes.

En la TSP, como en cualquier procedimiento de simultánea validación de un test psicológico (de inventario o cuestionario) y de su correspondiente constructo, la redacción primera del repertorio es todavía preexperimental y queda bajo la responsabilidad del investigador. A diferencia, sin embargo, del procedimiento de validación de constructos psicológicos, la TSP puede llegar. pronto a confirmar empíricamente la exhaustividad del «corpus» que construye y la consiguiente validez del instrumento (la lista o repertorio de frases) en orden a medir lo que pretende medir (el significado de un término presente en todas las frases). Basta para ello con pedir a diferentes grupos de sujetos que intenten completar una preexistente lista de frases con nuevos enunciados que pudieran suponer un imprevisto uso y contexto del término bajo consideración. Enseguida se llega a un límite en que aparecen redundancias de contexto y uso, según el juicio unánime de todos los hablantes. Conviene retener las redundancias dudosas, eliminando tan sólo las evidentes, unánimemente reconocidas, y con esta eliminación se da por cerrado el «corpus», el repertorio de frases que serán objeto de sustitución lexical.

Procedimientos semejantes a la TSP no son desconocidos, sino de uso corriente, entre los lingüístas. Hay que mencionar, en concreto, las pruebas de conmutación y de permutación, efectuadas como medio de contraste respectivamente a nivel paradigmático o de diferencias estructurales en la lengua y a nivel sintagmático o de secuencias del discurso. Son procedimientos de prueba con alcance conceptual definitorio tanto en fonología, en orden a la identificación de los fonemas en un lenguaje dado, cuanto en el estudio semántico del léxico, donde es posible definir las palabras como signos permutables mínimos (Hjemslev, 1943, 1971: 105-106; Roca-Pons, 1973: 139 y 349).

En cuanto al modelo semántico subyacente, cuyas características quiere explorar la TSP, se trata de un modelo topológico, espacial. De acuerdo con él, las relaciones de significado lingüístico serían metafóricamente descriptibles en términos de relaciones espaciales, de modo que la primera operación descriptiva del significado y también de su más elemental taxonomía se obtienen de la ubicación de cada palabra en un mapa léxico don- 
de se registran sus relaciones de contigüidad, proximidad, nexo o dirección.

Varias metáforas pueden especificar el modelo topográfico. La más sencilla de ellas, meramente lineal, es la de eje semántico, propuesta por Greimas (1966: 1971, 31-40) como unidad mínima de articulación de la significación, denominador común conjuntivo sobre el que disyuntivamente se destaca el sentido de los términos que ocupan sus dos extremos (figura 1). Cada término lingüístico aparece no en uno, sino en muchos ejes semánticos (figura 2), la totalidad de los cuales genera un espacio semántico multidimensional que encierra la totalidad de significados de una lengua.

Figura 1

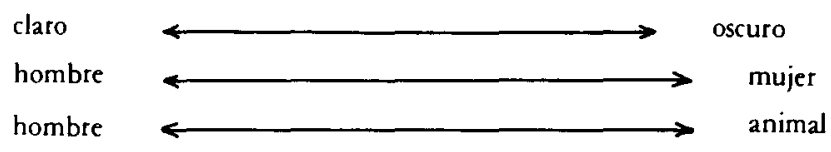

Ejemplos de ejes semänticos: dos términos polarmente opuestos sobre una misma dimensión.

Figura 2

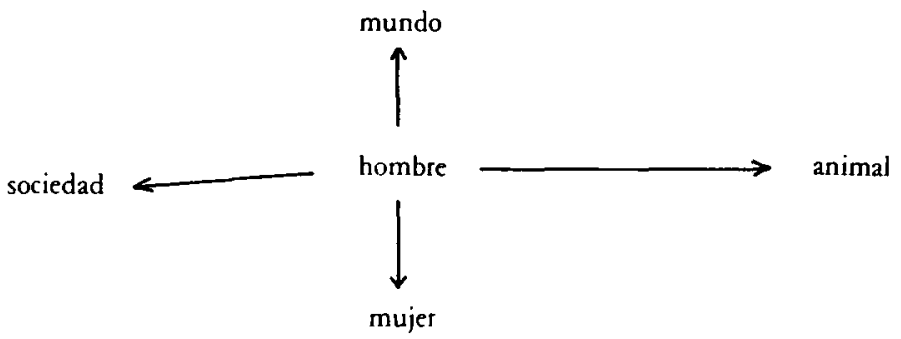

Algunos ejes semánticos en los que está situado el lexema "bombre*.

Los lingüístas consideran que la descripción exhaustiva de ese espacio total, del universo semántico de la lengua, es una tarea no sólo ímproba, sino en rigor inalcanzable, de la que debe desistirse. Se han aplicado, por eso, a acotar pequeñas parcelas del espacio semántico y a escribirlas adecuadamente. El propio Greimas (o.c. 192-196) se contenta con la somera tipificación de algunos «microuniversos semánticos» (concretamente: científicos, tecnológicos, ideológicos y axiológicos), tras haber presentado el "microuniverso» como un modelo, inmanente a la lengua, constituido por un pequeño número de categorías sémicas estructuradas, capaces de dar cuenta del contenido semántico de un discurso isótopo.

Más precisa y completa aparece la elaboración del modeló topológico en el concepto y teoría del campo semántico o campo léxico, inicialmente enunciada por Trier $(1931,1932)$ y Weisgerber $(1939,1954,1964)$ y acogida también por otros lingüistas (Ullman, 1951; Coseriu, 1977; Geckeler, $1971,1976)$. Los campos léxicos constituyen unidades relativamente pequeñas de léxico, cerradas y articuladas, que cubren espacios muy precisos 
de significación, referidos a las correspondientes áreas de objetos o conceptos. Campos léxicos estudiados han sido, por ejemplo, los relativos a colores, a relaciones de parentesco, a edades, a la velocidad. La propiedad fundamental del campo es la de cubrir sin huecos, exhaustivamente, en cualquier momento dado de la lengua, un sector de la visión del mundo. Los lingüístas que se manifiestan críticos con la teoría de los campos léxicos (Öhman, 1951; Oksaar, 1958; Kandler, 1959) han resaltado la imposibilidad de señalar con nitidez los límites donde empiezan y terminan dichos campos, que a veces se solapan, así como la de describir en tales términos la totalidad del universo semántico, que sólo muy parcialmente resultaría cubierto por los campos. También se ha objetado que son campos no tanto lingüísticos cuanto conceptuales, integrados por significantes culturales.

La última objección mencionada no tiene por qué dañar el propósito de investigar mediante TSP precisamente el significado cultural de ciertos signos lingüísticos. Esta investigación, aunque ocupada en el lenguaje, no se propone pertenecer a la lingüística o quedar confirmada en su ámbito disciplinar, y no está obligada, por tanto, a definir los campos semánticos específicamente por los lexemas y no por los conceptos. Por otra parte, la TSP puede aportar datos empíricos a la discusión sobre la posibilidad o imposibilidad de organizar el universo del significado en campos semánticos bien circunscritos, relativamente cerrados, aunque a la vez relacionados entre sí. En el uso que he hecho de ella, para dilucidar el significado de términos referidos a valores, constituye un instrumento adecuado para verificar y decidir si el conjunto de palabras de contenio axiológico forma un campo semántico en acepción análoga a la de Trier y Weisgerber —o acaso, un área más amplia integrada por varios campos semánticos-, o, por el contrario, no lo forman en absoluto y es ostensiblemente irreducible a la articulación en campos; mientras en la segunda resultaría crecientemente claro que, con la salvedad de algunos campos reducidos, claramente acotados, la mayor parte del espacio semántico no se deja describir en campos y necesita de otro modelo de descripción.

Con independencia de su contribución a la discusión del modelo de campo léxico y/o semántico, la TSP se adecúa perfectamente, de todos modos, a la exploración e identificación de los ejes semánticos conceptualizados por Greimas. Cada una de las sustituciones de que es suceptible un lexema puede ser reputada indicativa de un eje semántico donde el lexema se halla. Cada lexema está situado en una multiplicidad de ejes semánticos, pero en una multiplicidad determinada, limitada. Los lexemas respectiva y polarmente opuestos al lexema originario de referencia se encuentran, a su vez, en otros ejes semánticos y no sólo en el lugar terminal opuesto del primer eje considerado (figura 2). Un conjunto de estos ejes genera un espacio semántico multidimensional. que bien puede denominarse «microuniverso semántico», como hace Greimas, y que, desde luego, tampoco es ilimitado. Es más, en el trazado de ejes semánticos puede observarse que a una primera fase de multiplicación y expansión en la que cada eje a partir de sus lexemas terminales se ramifica en otros muchos, sigue otra fase, inversa a la anterior, en la que las nuevas ramificaciones vuelven a enlazar con ejes anteriores, clausurándose la red relacional en un espacio relativamente bien circunscrito, que no se expande ya más (figura 3).

La TSP puede ser utilizada para investigar cualquier microuniverso. Sólo la he puesto en práctica, sin embargo, en el que Greimas denomina "axiológico», microuniverso semántico de los valores. El avance que, en todo caso, supone la TSP respecto a los lingüístas es que, mientras éstos pro- 
Figura 3

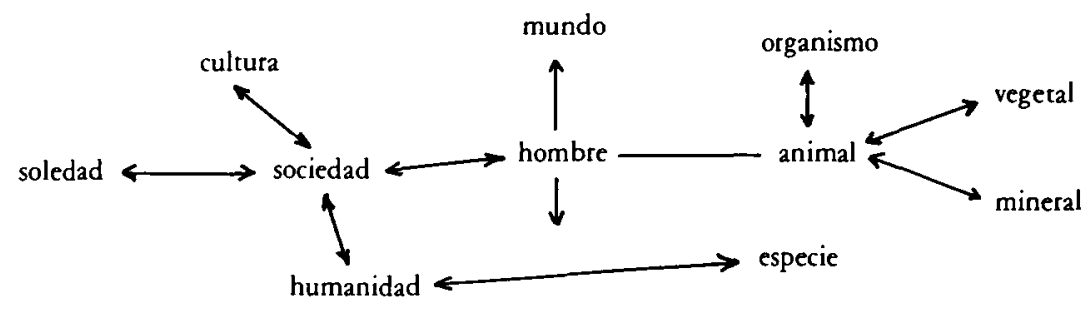

Ampliación de la figura 2 en una red de ejes semánticos que expanden las ramificaciones desde el "lexema bombre", aunque estableciendo también enlaces (cf. bumanidad-especie) que, tras la fase de expansión tienden a cerrar el conjunto en un sistema finito.

ceden a describir el espacio semántico a partir de su individual competencia de hablantes y de expertos en lenguaje, la TSP opera de manera menos fenomenológica y más objetiva, empírica y cuasi-experimental, recabando sus datos y descripción de muestras plurales de hablantes.

\subsection{En la psicología}

Hasta donde alcanzan mis noticias, ni en lingüistica ni en psicología ha operado nadie hasta la fecha con procedimientos, como los aquí descritos, de pruebas de sustitución de palabras. Con todo, igual que en la lingüística estructural, también en el ámbito de la psicología del lenguaje pueden señalarse algunas líneas de investigación con las que la TSP presenta ciertas afinidades, principalmente el diferencial semántico y la asociación de palabras.

El diferencial o diferenciador semántico es una técnica propuesta por Osgood, Suci y Tannenbaum (1957:1976, cf. también Snider y Osgood, 1969). Originariamente ideado para medir el significado connotativo de adjetivos, la aplicación del diferencial semántico se ha visto ampliada a otras mediciones en psicología: de las actitudes y de su cambio, de las diferencias individuales, de las emociones, de los procesos de comunicación social. Nos interesa aquí, de todos modos, en su propósito originario, muy cercano al de los lingüístas estructurales ocupados en descubrir y describir microuniversos o campos semánticos. Los creadores del diferencial semántico hablan precisamente de un «espacio semántico» que con su técnica tratan de identificar. Tal espacio, sin embargo, a diferencia de sus análogos entre los lingüístas, no es manifiesto, no aparece inmediato y ostensible en la estructura observable de los términos que lo forman. Es, por el contrario, una estructura latente, cuyo descubrimiento y descripción son posibles gracias a procedimientos varios de análisis factorial.

El material de base del diferencial semántico lo constituyen conjuntos de proposiciones de atribución o calificación, cuya forma sintáctica es: nombre sustantivo/verbo copulativo/predicado (adjetivo). El procedimiento para la recogida empírica de datos consiste en recabar de los sujetos que relacionen diferentes nombres sustantivos (cualesquiera nombres tomados del conjunto de los sustantivos: «mujer», abomba atómica», «los negros», «democracia», «Kennedy», «sueño», etcétera) con diferentes contraposiciones dicotómicas de adjetivos (bueno/malo, seguro/peligroso, 
bello/feo, etcétera), ubicando, además, aquellos nombres sobre una dimensión de siete valores mediante una marca señaladora, del siguiente modo:

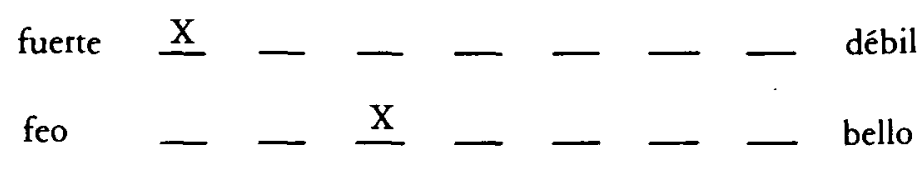

Las analogías con los ejes semánticos de Greimas saltan a la vista. Pero Osgood, Suci y Tannenbaum (1957) no se han interesado por los ejes o dimensiones bipolares de adjetivos más que como material empírico observable a partir del cual extraen -en un análisis factorial de componenteslas dimensiones de la estructura semántica latente que da razón del significado manifiesto de todos los adjetivos de la lengua, estructura que resulta tener tres factores principales: un factor I de evaluación, un factor II de potencia y un factor III de actividad.

A semejanza del diferencial semántico, la TSP constituye una técnica general, amplia y flexible, que puede ser operacionalizada en muy varios instrumentos específicos: los repertorios concretos que se construyan para su aplicación. También a semejanza suya permite la exploración de significados culturales, y no estrictamente lingüísticos, y en tal exploración, mediando procedimientos de análisis factorial, es capaz de detectar tanto componentes semánticos universales dentro de la comunidad lingüística, cuanto componentes diferenciales, vinculados a la jerga o al idiolecto de cada hablante, con las consiguientes posibilidades de aplicación como instrumento auxiliar de psicodiagnóstico, concretamente -en el principal uso más adelante referido- para la evaluación de actitudes y creencias. Con el diferencial semántico comparte, en fin, la TSP la circunstancia de trabajar con material lingüístico, presentado a los sujetos por escrito, no oralmente.

El señalamiento de algunas otras características del diferencial semántico servirá ya para indicar al propio tiempo en qué se aparta de él la TSP. El universo semántico explorado en el diferencial semántico es exclusivamente el de los adjetivos; el significado así descubierto resulta ser el connotativo, no el denotativo; el correlato psíquico que sus autores hipotetizan - de acuerdo con la conceptualización de Hull (1943) acerca de las «rm», o respuestas mediadoras fraccionales anticipadoras de meta-, constituye una representación evaluativa, evocadora o configuradora de emociones y estados afectivos. Con la TSP, en cambio, puede investigarse cualquier sintagma nominal (no sólo el adjetivo) y también verbal; el significado que se descubre es el denotativo tanto como el connotativo; su correlato psíquico lo constituyen toda clase de representaciones, no excluidas las propiamente cognitivas, de procesamiento de la información, es decir, representaciones con un contenido que se refiere al acto de describir y no sólo de evaluar el mundo de los objetos.

Aunque más laxa, alguna analogía puede señalarse también entre la TSP y los tradicionales tests o pruebas de asociación de palabras (Jung, 1918; Kent y Rosanoff, 1910; Rapaport, Gill y Schafer, 1946). Concebidos al principio como tests proyectivos, que trataban de reproducir y provocar con material tipificado la libre asociación de los psicoanalistas, posteriormente han sido utilizados como instrumentos de investigación psicolin- 
güística y, en particular, semánticas. Los numerosos aditamentos con que han sido completados y perfeccionados para mejorar su rigor y recisión (cf. la excelente reseña de Jodelet, 1972), no han sido bastantes, sin embargo, para sacarlos de la indeterminación en que vagan sus resultados, imposibles de interpretar, o bien de escaso interés teórico.

El problema interpretativo en la asociación de palabras yace en puntualizar el tipo o vínculo preciso de la asociación. A esta precisión contribuye la TSP, que descubre relaciones de asociación, pero de asociación semántica (no fonética, morfológica, de libre asociación u otra), de acuerdo con un procedimiento conocido por los lingüístas como «conmutación», que permite identificar dimensiones o ejes de significado. Respecto a los tests de asociación de palabras (y también al diferencial semántico que opera con palabras aisladas, nombres y adjetivos, fuera de contexto y sin integrarlos en frases o juicios explícitos), la TSP introduce, además, un elemento lingüístico decisivo: la frase, el acto de habla, la unidad mínima, pero compleja, de significación y de comunicación. Restituye con eso a la palabra a su lugar lingüístico propio, a la frase y al contexto, e investiga su significado en ese lugar y no en la abstracción de su aislamiento. Que la integración en frases y la prueba de conmutación constituyen, de todos modos, el natural complemento y afinamiento de la técnica de asociación de palabras, ha sido al menos sospechado por uno de los investigadores que trabajaron con esta técnica, S. M. Ervin (1963), quien completó la asociación con producción de frases y ulterior conmutación.

\section{DESCRIPCION}

\subsection{Procedimiento e instrucciones}

El material de trabajo en la TSP lo constituye una lista de frases que tienen todas ellas en común una palabra. La lista de frases ha de ser tan extensa como resulte necesario para recoger todos los usos posibles de la palabra y cerrar perfectamente el «corpus» de sus ocurrencias significativamente distintas. En caso de duda acerca de la clausura del «corpus», pecar por alargamiento de la lista debe ser preferido a hacerlo por acortamiento y defecto. No hay problema alguno por la repetición o redundancia de usos y acepciones, pero sí lo hay si no se asegura la exhaustividad. De todas maneras, no es nada arriesgado afirmar que ningún lexema necesitará más de 25 ó 30 frases para ver cubierto con creces el espacio de sus posibles usos. Como en cualquier género de prueba, el investigador corre con la inicial responsabilidad de elaborar la lista primera de frases, que, ulteriormente, a partir de sucesivas aplicaciones y de la recogida empírica de otros usos eventualmente no previstos puede ser ampliada y corregida.

Naturalmente, en una misma aplicación de la prueba a un determinado grupo de sujetos cabe reunir dos o más listas correspondientes a otras tantas palabras. Aún entonces, con todo, cada lista o conjunto de frases con su respectiva palabra común forma una unidad independiente que necesita de análisis también independiente.

La lista confeccionada se pasa bajo un título anodino (aencuesta», «estudio semántico», o cualquier otro que no despierte sentimientos, aquí infundados, de que la intimidad personal se halla implicada) a un grupo de personas, que en cada frase han de tachar la palabra común a todas las frases (palabra que se halla bajo investigación), y sustituirla por alguna otra 


\section{Estudios}

que a su juicio mantenga lo mejor posible el sentido de la frase. En cada frase la palabra sustitutiva puede ser distinta, pero también cabe repetir palabras ya utilizadas en sustituciones anteriores.

La sustitución más obvia, claro está, es la del sinónimo. Si en una investigación con la TSP estuviéramos interesados en averiguar el significado del término «conducta» en lenguaje común y pidiéramos sustituirlo por algún otro, con gran probabilidad lo veríamos reemplazado muchas veces por «comportamiento». Pero con eso, desde luego, no habríamos adelantado nada, pues «conducta» y «comportamiento» pueden pasar perfectamente por sinónimos. Para los objetivos deseados, conviene, pues, fijar la restricción de que la palabra por sustituir no sea reemplazada por sus sinónimos, e indicar taxativamente los sinónimos en cada caso excluidos, por ejemplo, descartando «equidad» entre los posibles sustitutos de «justicia» o «liberación» entre los sustitutos de alibertad».

Como muy bien puede suceder que alguna o algunas de las personas a quienes se pide la sustitución considere que en determinadas frases la palabra por sustituir, ella sola, resulta obligada $e$ insustituible, y que con otra cualquiera la frase se vacía de sentido, cabe permitir excepcionalmente la no sustitución, con dos variedades: una que consiste en subrayar la palabra, manteniéndola y sosteniendo con ello el significado de la frase entera, tal como reza, y otra consistente en tachar la frase entera por estimar que, al no tener sentido con ninguna otra palabra sustitutoria, acaso tampoco lo tiene tal como suena con la palabra por sustituir. Esta última posibilidad debe ser tomada en cuenta puesto que la TSP está concebida para investigar el significado de discursos axiológicos -moral, político, metafísico, religioso- que pueden ser repudiados como vacíos de sentido, en todo o en parte, por muchos sujetos.

Para ilustrar cómo se concreta la práctica efectiva de la sustitución, he ahí un texto de instrucciones según se trasmiten por escrito a los sujetos experimentales junto con la lista que deben trabajar:

«Este es un ejercicio de precisión verbal. La tarea consiste en la sustitución de una palabra, siempre la misma, por otras palabras dentro de cada frase de la serie. En concreto, se trata de tachar la palabra "XXX" y de sustituirla por alguna otra palabra que, a juicio de usted mantenga lo mejor posible el sentido general de la frase. La sustitución puede hacerse mediante una sola palabra o también, si es absolutamente preciso, mediante una breve perífrasis o conjunto de palabras.

En el caso de que, en alguna de las frases la palabra "XXX" se considere insustituible por ninguna otra palabra o perífrasis, se halla usted ante dos posibilidades:

1. Considerar que la frase tiene sentido tal como está, con la palabra "XXX" y sólo así lo tiene. En este caso debe subrayar la palabra " $\mathrm{XXX}$ ", dando a entender con ello que usted sostiene el sentido de la frase, sin poder efectuar en ella sustitución alguna.

2. ${ }^{2}$ Estimar, por el contrario, que la frase es vacía, carente de sentido, tanto con la palabra "XXX" como con cualquiera otra que pudiera ponerse en su lugar. En esta hipótesis ha de tachar la fràse entera.

La palabra por sustituir ( "XXX") es siempre la misma. Pero en su sustitución y a lo largo de la lista de frases pueden utilizarse tantas palabras como se necesiten y deseen. También es posible repetir una misma pa- 
labra, en sustitución de "XXX", cuantas veces haga falta para mantener el mejor sentido de la respectiva frase.»

En las instrucciones, el lugar de $₫ X X X »$ es ocupado por la palabra concreta que se está investigando: «libertad», «razón», «poder», «Dios», "pueblo», "conciencia», etcétera. Pero con esta mención de lexemas concretos para los que resulta particularmente idónea la TSP nos vemos introducidos ya en el tema del ámbito de aplicación de esta técnica.

\subsection{Ambito de aplicabilidad}

En principio, de suyo, la TSP puede ser urilizada en la investigación semántica de no importa qué lexemas del sintagma nominal o del verbal: nombres sustantivos, adjetivos, verbos. Su área de aplicación es más amplia que la del diferencial semántico, restringido a la exploración de los adjetivos y del espacio semántico generado por sus factores-componentes principales. Sin embargo, no se ve qué ganaríamos con aplicar un procedimiento bastante laborioso, como es la TSP, a la mayoría de los nombres y de los verbos. Es muy problemática la ganancia del procedimiento con términos susceptibles de definición ostensiva, como «mesa», «azul», "gato», "brincar", "humo» o «trompeta», cuyos directos referentes respectivos dejan escaso lugar a dudas. Incluso para palabras de un elevado nivel de abstracción, aunque propias todavía del lenguaje ordinario, como «polígono», «vertebrados», «relación», «argumentar», etcétera, existen procedimientos bien probados de investigación semántica, bajo la rúbrica de investigación de conceptos abstractos, que han de ser preferidos a la TSP. Esta comienza a exhibir su utilidad incremental allí donde la lejanía de las palabras y conceptos con respecto a unos referentes empíricos concretos y su consiguiente no ostensibilidad empírica derivan no ya de la abstracción clasificatoria o relacional, sino de la complejidad de las denotaciones y connotaciones que llevan culturalmente asignadas. Son los términos de discursos como el político, el moral, el metafísico, el religioso o el sentimental, los que pueden ser convenientemente analizados mediante la TSP, que, por su lado, está concebida para estudiar precisamente tal género de discursos.

Si se estima correcta la adecuación metodológica de la TSP al estudio de los discursos mencionados, entonces habría que proceder a una aplicación sistemática de la misma a los términos principales del léxico de la política, de la ética, de la religión, del sentimiento o de la metafísica. Esta mención de la metafísica debe entenderse pertinente no al lenguaje técnico de los filósofos, sino al lenguaje ordinario en lo que tiene de «cosmovisión» o de filosofía implícita. A él pertenecen términos como «razón», «sentido», «realidad», que no son exclusivos de los filósofos y que, con mayor o menor frecuencia aparecen también en el lenguaje cotidiano. De las posibles aplicaciones a estos diversos discursos he practicado algunas, que paso a reseñar a continuación.

\subsection{Repertorios construidos y aplicados}

Hasta la fecha he puesto en práctica la TSP con tres distintas formas, contituidas por sendos repertorios o listas de frases, susceptibles, por otro lado, de ulteriores versiones diferentes, en las condiciones que se dirá.

El repertorio 1 es de uso relativamente generalizado y de aplicación versátil a los diversos tipos de discurso por investigar, pues funciona con muy distintos términos. Consta del veinte frases, listadas en el cuadro 1. Las frases figuran en el cuadro en su forma vacía, dejando en hueco el sitio 


\section{Estudios}

\section{CUADRO 1}

Enunciados del repertorio 1, en su forma vacia. En la presentación llena, el repertorio queda completado ocupando en cada fase el hueco con la palabra que se desea investigar.

1. No renunciaría a

por nạda del mundo.

2. Aunque no estoy nada seguro de que el/la verdaders/a

pueda ser alcanzado/a, sin embargo, creo en él/ella.

3. Sobre su lápida está inscrito un sencillo epitafio: *Vivió y murio en/por/de/por la causa de/

4. Este incomparable poema es, en sustancia, un grandioso canto a

5. ¡Animo!, tienes ahora (a)

más cerca que nunca.

6. Si a consecuencia de algún vuelco en mis creencias y esperanzas actuales llegara a perder la fe en la solidaridad y en la amistad, en la democracia y en la convivencia pública, en las iglesias y en los partidos, continuaría. pienso, creyendo invenciblemente en

7. Tú crees que vale de mucho, pero a mí no me sirve de nada que justo en este momento me vengas hablándome de

8. Buda y San Francisco, cada uno a su modo, dieron testimonio de

9. Imagino la vida sin muchas cosas. No la puedo imaginar sin

10.

del lenguaje humano.

11. El/la

de los amos no es el/la mismo/a que el/la de los siervos.

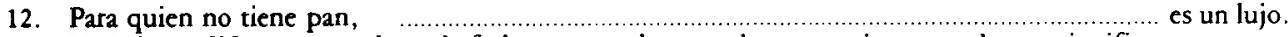

13. Nada he podido encontrar hasta la fecha que pueda reemplazar o equipararse a lo que significa para mí.

14. El mejor símbolo de aquella remota cultura lo representa la enigmática imagen encontrada en el centro del poblado, representación alegórica de ...................................................................................... según los arqueólogos.

15. El orador comenzó diciendo que el tema de ha sido y es, sin duda, el más importante para el hombre de todos los tiempos.

16. Al final de la novela, nuestro personaje ha perdido a

17. Desde luego, yo tengo necesidad de

18. Que me hayas hablado de me ha llegado al corazón.

19. Yo sé que un día, aunque yo acaso no lo vea, será por fin el triunfo de

20. No te juntes con quienes no creen en.

donde colocar el término sometido a estudio en una determinada aplicación de la TSP. La versatilidad de la lista 1 se manifiesta en que puede presentarse a los sujetos llenando el hueco con cualquiera de estos términos: «libertad», «amor», «Dios», pertenecientes respectivamente, como términos clave, al lenguaje político, sentimental y religioso. De hecho he aplicado la forma 1 con los referidos términos. Seguramente, además, puede ser también utilizada con otras palabras del microuniverso de los discursos axiológicos.

En aplicación de la TSP, el repertorio 1 es presentado en alguna de sus formas llenas, ocupados los vacíos con la correspondiente palabra bajo estudio. El repertorio, además, puede en su forma vacía ser utilizado para la identificación y medición de actitudes, creencias, adhesión a valores, etcétera. En este uso, a los sujetos no se les pide sustituir, sino al contrario, competar las frases, rellenar los huecos. Este es un procedimiento no original, pero distinto de la TSP. Tareas de completamiento de frases son utilizadas como medio de investigación en psicolingüística y en psicometría, aunque su utilización más difundida ha sido como técnica proyectiva en la que el comienzo de la frase (v. gr., «a mí me gustaría...»), es tan vago que 
puede el enunciado concluirse con cualquier apreciación subjetiva. En su forma vacía, el repertorio 1 bien puede ser considerado como una variedad del género de completamiento de frases con la especificación de que no busca proyecciones del sujeto, sino significaciones asociadas a sus actitudes y creencias.

La variedad vacía del repertorio 1 es susceptible de utilización y aplicación independiente de la TSP, es decir, como instrumento autónomo, con valor propio. Por mi parte, me he servido de ella como instrumento auxiliar de la TSP, sea para identificación de los términos más apropiados para el ejercicio de la sustitución, sea para comprobación, por un procedimiento independiente, de los ejes semánticos hallados mediante TSPे. Me he sérvido, además, de ella en dos modalidades diferentes de tarea: una, en que los sujetos rellenan los huecos de las frases poniendo cada vez la palabra que juzgan más oportuna, con libertad tanto para la repetición como para la multiplicidad de palabras; otra, en que se hallan obligados a escoger una sola y misma palabra para cubrir todos los vacíos y dar con eso sentido a todas y cada una de las frases. Es muy razonable conjeturar que la palabra así elegida ocupa un lugar central en el microuniverso de los discursos axiológicos de cada sujeto. El dato de que en una muestra de 54 sujetos, estudiantes universitarios de último curso de carrera, 20 de ellos escogieran la palabra alibertad» para conferir sentido a todas las frases del repertorio 1, en su forma vacía (el siguiente término en frecuencias era «amor»: 14 elecciones), es en sí mismo significativo para un conocimiento de las actitudes de los universitarios españoles en el momento actual; $y$ ha venido a sumarse a mi interés previo por el léxico político y por el contenido justo de ese término en el habla cotidiana, para determinar la confección de un segundo repertorio, para aplicación de la TSP con la palabra «libertad».

El repertorio 1, aunque posible núcleo de otros repertorios, es en sí mismo insuficiente. La insuficiencia deriva de su propia generalidad y versatilidad. Un conjunto de veinte frases, que aproximadamente por igual tienen sentido con la palabra «libertad», o «Dios», o «felicidad» y «amor», no puede recoger de modo exhaustivo la totalidad de los usos de cada una de ellas; recoge sólo usos comunes con otras palabras, no los suyos específicos; puede contribuir a delimitar el espacio semántico de los discursos axiológicos, pero no los ejes semánticos, todos de cada término implicado. En resumen: el repertorio 1 no cumple el requisito de clausura del «corpus» y necesita, para ese cumplimiento, ser ampliado y completado en repertorios no generalizados, particulares y propios de cada término sometido a estudio.

El repertorio 2 está integrado por frases donde figura la palabra . xlibertad», que los sujetos deben sustituir por alguna otra de acuerdo con las instrucciones habituales, ya mencionadas, de la TSP. Consta de las 20 frases del repertorio 1 , llenadas con el término alibertad» y de otras 10 recogidas en el cuadro 2 . Aunque no restringido en su uso a ambos lenguajes, «libertad» se considera un término central en el lenguaje político y también, hasta cierto punto, en el de la ética. La investigación a partir del repertorio 2 permite la identificación de ejes semánticos en estos dos microuniversos discursivos.

He confeccionado un repertorio 3 con la palabra «Dios» para la exploración del lenguaje religioso. El nombre de «Dios» presenta algunas peculiaridades semánticas que lo singularizan frente a otros sustanitivos de los discursos axiológicos: se halla más remoto que ningún otro de los referentes empíricos susceptibles de ostensión; funciona como signo lingüístico de 


\section{CUADRO 2}

Enunciamos que, para el estudio de la palabra alibertad, se añaden a los del repertorio 1 (cf. cuadro 1), constituyendo así el repertorio 2.

21. ¡Ah!, cómo envidio la (libertad) de los pájaros.

22. Un portavoz del Gobierno ha asegurado que en el país no se ha cometido ningún atentado contra la (libertad) por parte de los poderes públicos.

23. Todos los Códigos penales contemplan contemplan penas de privación de (libertad).

24. (Libertad), ¿Cuăntos crímenes se han cometido en tu nombre!

25. El pueblo entero se echó a la calle gritando: (ilibertad!).

26. Tienes (libertad) de hacer lo que quieras.

27. Que es mi barco, mi tesoro, que es mi Dios la (litertad)...

28. La intolerancia parece tan connatural a la especie humana que la (libertad) no ha existido en casi ninguna parte.

29. Frente a todas las variedades de Antiguo Régimen, las revoluciones modernas coinciden en un lema que puede compendiarse en tres palabras: igualdad, (libertad) y fraternidad.

30. No pide (libertad) más que el esclavo; el hombre libre pide amor.

un concepto abstracto (y hasta ahí «Dios» o la «divinidad» es tan abstracto como -o más abstracto que - la «libertad», el «sentido» o la «conciencia») $y$, al propio tiempo, como nombre de una figura personal que, a diferencia de otras abstracciones, puede ser objeto de interpelación en segunda persona. Esta última característica hace que el «corpus» de los posibles usos del nombre de Dios sea más amplio que el de los demás términos considerados en este informe y que, en consecuencia, el repertorio 3 haya venido a resultar también el más extenso, con un total de 60 frases, muchas de las cuales, por lo demás, son redundantes e innecesarias, como también lo son algunas en los repertorios 1 y 2 , por resultar pertinentes a un sólo y mismo uso del correspondiente lexema.

Por su longitud no reproduzco las 60 frases del repertorio 3. En su lugar ofrezco una lista de los diversos usos lingüísticos en que puede aparecer el nombre de Dios (cf. cuadro 3), de acuerdo con un análisis descriptivo que he justificado en otro trabajo (Fierro, 1976). La elaboración de repertorios para estudio semántico de un término cualquiera mediante la TSP

\section{CUADRO 3}

Usos o juegos de lenguaje en los que puede aparecer el lexema "Dios" y que ban servido para elaborar el repertorio 3. Para su explicación, cf. Fierro, 1976.

- Anuncio o mensaje.

- Catequesis, enseñanza o adoctrinamiento religioso.

- Credo o profesión de fe.

- Enunciado dogmático.

- Lenguaje de esperanza de salvación.

- Relato de experiencia religiosa.

- Expresión de necesidad o deseo.

- Oración, plegaria, invocación.

- Profecía o mandato en nombre de Dios.

- Teología.

- Blasfemia.

- Juramento.

- Bendición.

- Doxología o exclamación de alabanza.

Estudios de Psicología n. ${ }^{\circ}$ S y $6-1981$ 
supone el previo establecimiento de todos los usos del término en forma de listados semejantes al del citado cuadro, cuyo contenido resulta, por tanto, ilustrativo del género de análisis requerido para poner en marcha la investigación.

\subsection{Variedades de aplicación}

No ha sido mi propósito comunicar e interpretar aquí los datos recogidos en sus diferentes aplicaciones practicadas, lo que llevaría mucho espacio y queda para comunicaciones posteriores, sino informar acerca de una técnica y de sus posibles usos. Además de las variedades de uso ya explicadas a propósito de los diversos repertorios y de las dos formas, vacía y llena, del repertorio 1 , restan por reseñar algunos procedimientos complementarios de los que se ha servido en conjunción con la TSP.

He combinado esa técnica con una prueba de memoria semántica a largo plazo de acuerdo con procedimientos tradicionalmente utilizados (cf. Laffal, 1955) para medir la firmeza de la asociación en listas de asociación de palabras. A los mismos sujetos que habían efectuado un ejercicio de sustitución de palabras les pedí, cuatro meses más tarde, que volvieran a repetir el ejercicio, con la misma lista, pero esforzándose por recordar y tratando de sustituir otra vez ahora con la misma palabra que emplearon en la primera ocasión. Este procedimiento permite, obviamente, discriminar entre las situaciones efectuadas sobre lazos accidentales, determinados por mecanismos de alibre asociación», por ocurrencias transitorias en el momento de la prueba, y aquellas otras verdaderamente interesantes para el análisis semántico, basadas en relaciones estructurales de significado y de codificación y almacenamiento semántico permanente.

También he unido la aplicación del repertorio 1, en su forma vacía, con el procedimiento del diferencial semántico. En el curso de una misma sesión se pidió a los sujetos rellenar dicho repertorio y también efectuar una evaluación de diez términos distintos - seleccionados entre los más frecuentes en la tarea sea de relleno, sea de sustitución en el repertorio 1 -, sobre un total de 20 dimensiones bipolares de adjetivos, de acuerdo con el procedimiento ordinario de Osgood, Suci y Tannenbaum (1957). Esta combinación se ordena a verificar si los términos sustitutorios o alternativos, respectivamente, en la TSP y en la tarea de llenar el repertorio 1, forma vacía, aparecen también con perfiles semejantes y ocupan posiciones contiguas en el espacio semántico generado por los tres factores subyacentes principales identificados por Osgood, Suci y Tannenbaum (1957). Esta combinación se ordena a verificar si los términos sustitutorios o alternativos, respectivamente, en la TSP y en la tarea de llenar el repertorio 1 , forma vacía, aparecen también con perfiles semejantes y ocupan posiciones contiguas en el espacio semántico generado por los tres factores principales identificados por los referidos autores.

El repertorio 3, en fin, parecía particularmente idóneo para someter a prueba con él dos diferentes hipótesis. La primera dice que las disparidades de creencias y actitudes - religiosas en este caso- no determina diferencias de orden estrictamente semántico, de significado de los términos -aquí, el nombre de Dios- por parte de los portadores de las dispares creencias. Concretamente según la hipótesis, la creencia o increencia religiosa, o los diversos géneros y grados de creencia no modificarían la identidad sustancial del significado de la palabra «Dios» (así, Dumery, 1959; en contra, autores de orientación confesional: Holmer, 1961; Oden, 1965; Vergote, 1974). Es un mismo y solo «Dios» el confesado por el creyente y el 


\section{Estudios}

rechazado por el increyente. Esta hipótesis ha sido contrastada empíricamente por dos procedimientos distintos: averiguando por vía independiente la creencia religiosa de los sujetos encuestados con el repertorio 3 ; comparando resultados de una muestra - que se supone heterogénea- de universitarios con los de una muestra de estudiantes eclesiásticos en curso de preparación al sacerdocio, a los que se supone homogéneos y relativamente uniformes en su creencia religiosa. Aunque el presente informe no se proponga comunicar resultados, cabe anticipar que la hipótesis ha quedado confirmada - con las evidencias y los límites que deberá puntualizar en otra comunicación-y que tal comprobación invita a replicar los resultados con otros términos, averiguando, por ejemplo, si personas de talante - eventualmente de militancia - liberal, libertaria y fascista, comparten, de todos modos - según predice la hipótesis - un mismo contenido semántico de la palabra «libertad», respectivamente respetada, exaltada y denigrada en bien dispares posiciones, pero conceptuada de manera semejante, en una manera, además, que hace posible la comunicación de unos con otros, aunque sólo sea la comunicación recíproca de que se está en desacuerdo, de que persisten irreducibles discrepancias sobre el objeto del significado. La hipótesis alternativa aseguraría, por el contrario, que la libertad afirmada por el hombre liberal no es la misma que la negada por el hombre autoritario, que el Dios de los creyentes no es el mismo que el de los ateos y que otro tanto sucede con el restante censo de lexemas de los discursos axiológicos.

Una segunda hipótesis sometida a prueba con el repertorio 3, complementaria y, en parte, correctora de la anterior, se refiere a la posibilidad de influenciar la representación semántica de un término del microuniverso axiológico mediante el suministro de información al respecto. Un diseño experimental parecido ha sido utilizado ya por Deconchy (1975) para valorar ciertos efectos que en el sentimiento de afiliación al grupo religioso produce la «inyección de información científica». En nuestro caso, la variable manipulada, independiente, consistió en informar a los sujetos experimentales acerca del análisis positivista o empirista (cf. 1.1) de los enunciados religiosos y éticos, emitiendo la hipótesis de que esta información ejercería influencia en el modo de sustituir (variable dependiente) el término "Dios» en el repertorio 3, con el efecto de incrementar el número de veces o frases en que dicho término quedaría sin sustituir, efecto, además, probablemente diferenciado en dos direcciones distintas; especificado en sujetos religiosos por un aumento de las frases sin sustitución, pero confirmadas, y en sujetos increyentes, por un aumento semejante, pero con tachadura de la frase (de acuerdo con las instrucciones recogidas en 2.1). el grupo para esta prueba estuvo integrado por estudiantes universitarios de primer año de carrera, a los que razonablemente cabe presumir receptivos al suministro de información. Esta les fue administrada en forma de una clase ordinaria, impartida por uno de sus profesores habituales e inserta en el conjunto del programa académico, en el momento en que éste llegaba al estudio del lenguaje. La estrategia experimental tomó a un solo grupo de estudiantes como control de sí mismo, en un diseño antes-después. Los sujetos efectuaron la sustitución en los 30 primeros enunciados del repertorio 3 , antes de la leción informativa, después de la cual hicieron otro tanto con las restantes 30 frases, justificándose ante ellos la partición de dos sesiones por la longitud de la prueba. En el momento de redactar el presente informe los resultados de esta última investigación se hallan bajo estudio, todavía sin interpietar. 
Las aplicaciones practicadas no agotan los posibles usos de la TSP, ni siquiera las principales líneas de investigación a que se presta. Puede constituir instrumento de la psicología evolutiva para registrar procesos de la formación del lenguaje, en particular, para resolver en qué sentido y hasta qué punto el significado de los lexemas bajo consideración aparece entero, de una vez, como están inclinados a creer los estructuralistas (cf. Derrida, 1967, 1971, p. 158), o, más bien, por el contrario se constituye progresivamente como en principio tenderá a suponer el psicólogo, examinando en todo caso cómo y cuáles son las reorganizaciones semánticas que se producen en el niño en el proceso de adquisición del lenguaje abstracto de los valores. Puede también, a semejanza del diferencial semántico, ser utilizado para diagnóstico psicopatológico, sobre todo, para evaluación de la percepción de la realidad social, aunque, naturalmente, este último uso requiere la previa confección de perfiles característicos dentro de una sociedad y específicos para cada uno de los términos.

Tratamiento estadístico particularmente indicado para los datos resultantes de la TSP será el análisis factorial. A semejanza otra vez del diferencia semántico, se trata de reducir, mediante análisis de componentes principales o mediante cualquier otro procedimiento de factorización, unos ejes o dimensiones manifiestos (aparentes en los protocolos de los sujetos), pero superficiales a una estructura latente de dimensiones o factores que, con mayor parsimonia, justifiquen la varianza de los primeros.

El análisis factorial del significado a partir de datos producidos con la TSP tiene una finalidad análoga a la que se le asigna y reconoce en la mayoría de sus usos en psicología: contribuir a una taxonomía más razonable, económica y profunda, que la que podría derivarse de una clasificación de fenómenos manifiestos. Las operaciones descriptivas taxonómicas figuran, con toda seguridad, entre las más rudimentarias de la ciencia. Pero como repetidamente, en otro contexto, ha destacado Eysenck (1952, 1971, p. 5-6 y 34; 1967: 1970, p. 18-19), por elementales que sean, son operaciones necesarias e imprescindibles; constituyen en la investigación pasos primeros y, por eso mismo, pasos previos, sin los cuales no hay ulterior avance.

La TSP no proporciona datos que contribuyan a la explicación del significado, al establecimiento de las leyes que lo rigen, al contraste de hipótesis emitidas a propósito. Es una limitación suya, que no cabe ser ocultada. Sirve a propósitos empíricos más modestos, hasta cierto punto rudimentarios, aunque nada despreciables: propósitos descriptivos y taxonómicos. Para una determinada comunidad cultural y no sólo linguiística (el espacio semántico de alibertad» no será sustancialmente diferente del de «liberté», «freedom» o «Freiheit»), es capaz de describir y ordenar dimensiones patentes y latentes de significado de ciertos lexemas abstractos para los que no tenemos mejores instrumentos de investigación. 


\section{Resumen}

Se presenta un método nuevo de estudio semántico del lenguaje: la técnica de sustitución de palabras (TSP), así como algunas pruebas concretas para aplicación de dicha técnica general. Las pruebas consisten en repertorios de frases donde figura la palabra por investigar en cada caso, palabra que los sujetos que realizan la prueba han de sustituir por alguna o algunas otras, tratando de conservar el sentido de la frase. Aunque constituye una técnica general de investigaión semántica, destacan sus ventajas en el estudio de ciertos lenguajes: político, ético, religioso y filosófico.

\section{Resumé}

On expose une nouvelle méthode d'étude sémantique du langage et de la parole: la technique de substitution de mots (TSP) ainsi que des concretes illustrations practiques de son application: des repertoires des phrases avec le mot sous recherche dans chaque cas, mot qui doit dans l'épreuve être substituée par une autre. Bien qu'il s'agit d'une technique générale de recherche sémantique, ses avantages sont remaquables surtout dans l'étude des certain discours: politique, éthique, religieux, philosophique.

\section{Summary}

The aim of this work is to present a new method for the semantic study of language: the word substitution technique (TSP), as well as some concrete examples of its general application. These consist of series of sentences in which appears the word in question in each case, a word which the subjects performing the test must substitute for another or others whilst trying to maintain the meaning of the original sentence. Although it is a general technique in research into semantics, it has clear advantages in the stady of certain language types, such as the political, ethical, religious and philosophical.

\section{Referencias}

AUSTIN, J. L. How to do things with words. Oxford: Clarendon, 1962 (trad. cast. Palabras y acciones. Buenos Aires: Paidós, 1972).

AYER, A. J. (ed.) El positivismo lógico. México: Fondo de Cultura económica, 1965.

AYER, A. J. Lenguaje, verdad y lógica. Barcelona: Martínez Roca, 1971.

CARNAP, RUDOLF. Uberwindung der Metaphysik durch logische Analyse: Erkenntnis, 2 (1931).

COSERIU, EUGENIO. Principios de Semäntica Estructural. Madrid: Gredos, 1977.

DECONCHY, JEAN-PIERRE. L'image des acommunautés de base comme support cognitif pour des croyances menacées dans leurs fondements krationels", en CISR, Changement social et religion, Lille, 1975.

DERRIDA, JACQUES. De la grammatologie. París: Minuit, 1967. (De la gramatología. Buenos Aires: Siglo XXI, 1971).

DUMERRY, HENRI. La foi n'est pas un cri. París, Seuil, 1959. 
ERVIN, S. M. Correlates of associative frequency. Journal of verbal leaming and verbal behavoir, 1963, 422-431. EYSENCK, H. J. The scientific study of personality. Londres: Routledge and Kegan Paul, 1952. (Estudio cientifico de la personalidad. Buenos Aires: Paidós, 1971.)

EYSENCK, H. J. The Biological Basis of Personality. Springfield, Illinois: Charles C. Thomas, Publisher, 1967. (Fundamentos biológicos de la personalidad. Barcelona: Fontanella, 1970.)

FIERRO, ALFREDO. Semäntica del lenguaje religioso. Madrid: Fundación Juan March, 1976.

GECKELER, HORST. Strukturelle Semantik und Wortfeldtheorie. Munich: W. Fink, 1971. (Semántica estructural y teoría del campo léxico. Madrid: Gredos, 1976.)

GREIMAS, ALGIRDAS JULIEN. Sémantique structurale. París: Larousse, 1966. (Semäntica estructural. Madrid: Gredos, 1971.)

HARRIS, ZELI.IG, S. Methods in structural linguistics. Chicago: Univ. Chicago Press, 1951.

HARRIS, ZELLIG, S. Distributional Structure. Word, 1954, 146-162.

HJELMSLEV, LOUIS. Omkring Sprogteoriens Grundlaeggelse. En: Festskrift udg. Kobehavns Universitet, nov. 1943. (Prolegómenos a una teoría del lenguaje. Madrid: Gredos, 1971.)

HOLMER, P. L. Scientific Language and the Language of Religion. Journal for Scientific Study of Religion, 1961, 42-55.

JODELET, FRANÇOIS. L'association verbale. En: P. Fraisse y J. Piaget (eds.) Traité de psychologie expérimentale, Vol. 8: Language, communication et décision. París: P.U.F., 1972.

JOOS, MARTIN. Readings in Linguistics, vol. I, The Development of descriptive Linguistics in America. Chicago: 1957

JUNG, Carl G. Studies in Word Association. Nueva York: Dood, Mead y Co., 1918.

KANDLER, G. Die Lücke im sprachlichen Weltbild. En: Sprache-Schlüssel zur Welt. Festschrift für L. Weisgerber. Düsseldorf, 1959, 256-270.

KENT, G. H. y ROSANOFF, A. J. A study of association in insanity. American Journal of Insanity, 1910, 37-96 y $317-390$.

LAFFAL, J. Response faults in word association as a function of response entropy. Journal of abnormal and social Psychology, 1955, 265-270.

ODEN, T. Révélation et psychoterapie. Nouvelle revue Théologique, 1965, 789-801.

OHMAN, S. Wortinhalt und Weltbild. Vergleichende und methodologische Studien zu Bedeutungslebre und Wortfeldtheorie. Estocolmo, 1951.

OKSAAR, E. Semantische Studien im Sinnbereich der Schnelligkeit. Estocolmo/Upsala: Acta Universitatis Stockholmiensis, 1958

OSGOOD, CHARLES E., SUCI, GEORGE J. y TANNENBAUM, PERCY H. The measurement of meaning. Urbana, Ill.: Univ. Illinois Press, 1957. (La medida del significado. Madrid: Gredos, 1976.)

PIKE, KENNETH L. El lenguaje como conducta. En: F. García (ed.), Presentación del lenguaje. Madrid: Taurus, 1972.

RAPAPORT, D., GILL, M. y SCHAFER, R. Diagnostic Psychological Testing. Chicago: Year Book Publishers, 1946.

RYLE, GILBERT. The concept of Mind. Londres: Hutchinson, 1949.

ROCA.PONS, J. El lenguaje. Barcelona: Teide, 1973.

SEARLE, JOHN R. Speech Acts. An Essay in the Phylosophy of Language. Cambridge: University Press, 1969. (Trad. cast.: ¿Qué es un acto de habla? Valencia: Universidad, 1977.)

SNIDER, J. y OSGOOD, C. (eds). Semantic Differential Technique. Chicago: Aldine, 1969.

TRIER. JOST. Der deutsche Wortschatz im Sinnbezirk des Verstandes. Heidelberg, 1931.

TRIER, JOST. Sprachliche Felder. Zeitschrift für Deutsche Bildung. 1932, 417-427.)

ULIMANN, STEPHEN. The Principles of Semantics. Oxford: Blackwell, 1951.

VERGOTE, ANTOINE. Interprétation du langage religieux. París: Seuil, 1974.

WEISGERBER, LEO. Die volkhaften Kräfte der Muttersprache. Francfort, 1939.

WEISGERBER, LEO. Die Sprachfelder in der geistigen Erschliessung der Welt. Festschrift für Jost Trier zu seinem 60 Geburtstag. Meisenheim/Glan, 1954, 34-49.

WEISGERBER, LEO. Das Menschbeitgesetz der Sprache als Grundlage der Sprachwissenschaft. Heidelberg, 1964.

WELLS, R. S. Inmediate Constituents Language, 1947.

WITTGENSTEIN, LUDWIG. Philosophical Investigations. Oxford: Blackwell, 1958.

WOTJAK, GERD. Untersucbungen zur Struktur der Bedeutung. Berlín: Akademie Verlag, 1977. (Investigaciones sobre la estructura del significado. Madrid: Gredos, 1979.) 